Artikel Penelitian

\title{
Gambaran Derajat Varises Esofagus Berdasarkan Beratnya Sirosis Hepatis
}

Yestria Elfatma ${ }^{1}$, Arnelis $^{2}$, Nice Rachmawati ${ }^{3}$

\section{Abstrak}

Sirosis hepatis adalah suatu keadaan patologis yang menggambarkan stadium akhir fibrosis hepatik yang berlangsung progresif. Varises esofagus merupakan salah satu komplikasi tersering sirosis hepatis. Berat ringannya sirosis hepatis dapat dinilai dengan menggunakan klasifikasi Child Pugh. Tujuan penelitian ini adalah menentukan hubungan antara beratnya sirosis hepatis dan derajat varises esofagus. Penelitian ini adalah studi analitik menggunakan desain cross sectional study dengan jumlah sampel sebanyak 66 orang penderita sirosis hepatis yang dirawat inap di bagian Penyakit Dalam periode 2012-2013. Data dikumpulkan melalui catatan rekam medik yang kemudian di analisis melalui uji chi-square pada derajat kepercayaan 95\% (0,05). Dari hasil penelitian didapatkan varises esofagus pada pasien sirosis hepatis sebanyak $46 \%$ dengan insiden derajat varises esofagus paling banyak pada grade III $71,2 \%$ dan beratnya sirosis hepatis paling banyak pada Child C $47 \%$. Hasil uji statistik chi-square menunjukkan adanya hubungan antara derajat varises esofagus berdasarkan beratnya sirosis hepatis $(p=0,033)$. Simpulan studi ini ialah terdapat hubungan yang bermakna antara derajat varises esofagus dan beratnya sirosis hepatis.

Kata kunci: sirosis hepatis, varises esofagus

\begin{abstract}
Liver cirrhosis is a pathological condition which describes the end-stage of hepatic fibrosis that occurs progressively. Esophageal varices is one of the most common complication of liver cirrhosis. Severity of liver cirrhosis can be assessed by using the Child Pugh classification. The objective of this study was to determine the relation between the severity of liver cirrhosis and the degree of esophageal varices. This study was a analytic cross sectional study design using 66 patients with liver cirrhosis who were hospitalized within 2012-2013. Data were collected through a medical record which was analyzed by chi-square test at $95 \%$ confidence level (0.05). The result was made with esophageal varices found in $46 \%$ patients with liver cirrhosis and the most commonly found incidence of esophageal varices degree is grade III as much as $71.2 \%$ and the severity of liver cirrhosis is child C as much as $47 \%$. The result of the chi-square statistical test showed there is association between the degree of esophageal varices with hepatic cirrhosis severity $(p=0.033)$. In conclusion, there is significant relation between the degree of esophageal varices and the severity of liver cirrhosis.
\end{abstract}

Keywords: liver cirrhosis, esophageal varices

Affiliasi penulis:: 1. Prodi Profesi Dokter FK Unand (Fakultas Kedokteran Universitas Andalas Padang), 2. Bagian Penyakit Dalam FK Unand, 3. Bagian Anak FK Unand/RSUP DR. M.Djamil Korespondensi: Yestria Elfatma, email:yestria@yahoo.com, Telp: 08994670566

\section{PENDAHULUAN}

Sirosis hepatis adalah suatu keadaan patologis yang menggambarkan stadium akhir fibrosis hepatik yang berlangsung progresif. Kerusakan sel-sel hati ini akan berlanjut menjadi gangguan dari susunan hepar dan peningkatan vaskularisasi yang menyebabkan terjadinya varises atau pelebaran pembuluh darah di daerah gaster maupun esophagus. ${ }^{1}$

Sirosis hepatis menempati urutan ke tujuh penyebab kematian di dunia. Sekitar 25.000 orang meninggal setiap tahunnya akibat penyakit ini. 
Penelitian oleh Jang di Korea menyatakan bahwa sirosis hepatis adalah salah satu penyebab morbiditas dan mortalitas di Korea dan menduduki urutan kedelapan penyebab kematian pada tahun 2007 . $^{2,3}$

Di Indonesia belum terdapat data yang dapat merepresentasikan jumlah penderita sirosis hepatis secara akurat. Menurut laporan rumah sakit umum pemerintah di Indonesia, rata-rata prevalensi sirosis hepatis adalah $3,5 \%$ dari seluruh pasien yang dirawat di bagian Penyakit Dalam, atau rata-rata $47,7 \%$ dari seluruh pasien penyakit hati yang dirawat. ${ }^{4}$

Data di Bangsal Penyakit Dalam RSUP. DR. M. Djamil Padang pada periode Januari 1999 sampai dengan Desember 2000 dari 5181 pasien yang dirawat, 597 (11,52\%) menderita penyakit hati dan 388 $(64,99 \%)$ disebabkan oleh sirosis hepatis. Periode Januari 2006 hingga Desember 2006, 241 orang pederita sirosis hepatis dirawat di Bagian Penyakit Dalam RS. Dr. M. Djamil Padang. Periode 2009 tercatat 220 pasien yang dirawat dengan sirosis hati dan sedikit meningkat pada periode 2010 yaitu 317 pasien. Jumlah pasien sirosis hepatis yang dirawat pada tahun 2011 mengalami penurunan sebanyak 183 pasien. Rata-rata pasien yang dirawat di Bagian Penyakit Dalam RS. Dr. M. Djamil Padang dari tahun 2009-2011 adalah 240 orang. $^{5-7}$

Morbiditas dan mortalitas sirosis hepatis tinggi akibat komplikasinya. Ada 184 pasien sirosis hepatis pada penelitian di RSUD dr. Soedarso dari tahun 2008-2010 ditemukan sebanyak 116 pasien sirosis hepatis $(63,04 \%)$ telah mengalami komplikasi. Komplikasi tersering adalah perdarahan saluran cerna atas sebanyak 92 (50\%) kasus, diikuti dengan ensefalopati hepatik sebanyak $33(17,93 \%)$ kasus, dan dilanjutkan karsinoma hepatoselular. Kualitas hidup pasien sirosis hepatis diperbaiki dengan pencegahan dan penanganan komplikasinya. ${ }^{8,9}$

Sekitar $50 \%$ pasien dengan sirosis hepatis akan mengalami varises. Frekuensi varises esofagus sekitar 30\%-70\%, sedangkan varises gaster sekitar $5 \%-33 \%$. Sepertiga pasien dengan varises akan terjadi perdarahan yang serius dari varisesnya. Semakin tinggi derajat varises esofagus maka akan semakin tinggi juga kemungkinan untuk terjadinya perdarahan. Varises esofagus memiliki dampak klinis yang sangat besar dengan mortalitas $17 \%-42 \%$ setiap terjadinya perdarahan. ${ }^{10}$

Derajat varises esofagus merupakan salah satu faktor penyebab terjadinya perdarahan akut dan perdarahan berulang. Perdarahan pada esofagus merupakan penyebab kematian utama pada sirosis hepatis, akan tetapi episode derajat perdarahan tiap pasien bervariasi dari yang terbatas sampai kematian. Kriteria untuk prognosis yang buruk adalah terjadinya perdarahan yang lama, kegagalan pengontrolan perdarahan dan terjadinya perdarahan berulang. Semua faktor tersebut juga tergantung dari beratnya disfungsi penyakit dasar hati. Kelainan fungsi hati ini dapat dievaluasi dengan klasifikasi Child-Pugh yang merupakan faktor risiko untuk perdarahan. ${ }^{11}$

Tujuan penelitian ini adalah untuk mengetahui hubungan derajat varises esofagus dengan beratnya sirosis hepatis pada pasien rawat inap di Bagian Penyakit Dalam RSUP DR. M. Djamil Padang pada periode 1 Januari 2012 hingga 31 Desember 2012.

\section{METODE}

Penelitian ini dilakukan di bagian rekam medik RSUP DR. M. Djamil Padang dari September 2013 sampai Maret 2014. Sampel adalah semua pasien sirosis hepatis yang disertai varises esofagus berdasarkan hasil endoskopi yang memiliki kelengkapan data rekam medik, tidak menderita penyakit lain yang dapat mengganggu hasil penelitian seperti keganasan, penyakit darah dan lain-lain. Pengambilan sampel menggunakan teknik total sampling.

\section{HASIL}

Data rekam medik yang dikumpulkan selama periode 1 Januari 2012 sampai dengan 31 Desember 2013 ditemukan 422 kasus sirosis hepatis dan 194 kasus (46\%) disertai varises esofagus yang dirawat di Bagian Penyakit Dalam RSUP DR. M.Djamil Padang. Pada tahun 2012 didapatkan sebanyak 228 pasien sirosis hepatis dan 104 (45,6\%) dengan varises esofagus, sedangkan tahun 2013 ditemukan sebanyak 194 pasien sirosis hepatis dan $90(46,4 \%)$ dengan varises esofagus. Dari 194 penderita sirosis hepatis yang disertai varises esofagus, hanya 66 (34\%) yang 
memenuhi kriteria inklusi dan ekslusi dan dapat dijadikan sampel. Berikut adalah tabel karakteristik sampel penelitian.

Tabel 1. Karakteristik subyek penelitian

\begin{tabular}{lcc}
\hline \multicolumn{1}{c}{ Variabel } & $\mathbf{n}(\%)$ & Rerata \pm SD \\
\hline Jenis Kelamin & & \\
Pria & $50(75,8 \%)$ & \\
Wanita & $16(24,2 \%)$ & \\
Umur & & $51,8 \pm 10,8$ \\
Albumin & & $2,9 \pm 0,6$ \\
Bilirubin & & $2,7 \pm 2,5$ \\
ProtrombinTime & & $16,3 \pm 4,8$ \\
Asites & & \\
Tidak ada & $15(22,7 \%)$ & \\
Minimal & $16(24,2 \%)$ & \\
Sedang-Berat & $35(53,1 \%)$ & \\
Ensefalopati & & \\
Tidak ada & $57(86,4 \%)$ & \\
Grade 1-2 & $8(12,1 \%)$ & \\
Grade 3-4 & $1(1,5 \%)$ & \\
\hline
\end{tabular}

Berdasarkan Tabel 1 menunjukkan penderita sirosis hepatis lebih banyak pada laki-laki dibandingkan perempuan yaitu 50 laki-laki $(75,8 \%)$ dan 16 perempuan (24,2\%) dengan perbandingan 3:1. Terjadi peningkatan kadar albumin, bilirubin dan protrombin time dengan rata-rata 2,9 $( \pm 0,6), 2,7( \pm$ $2,5)$ dan $16,3( \pm 4,8)$. Ada banyak terjadi penumpukan cairan di rongga perut (asites) dengan derajat sedangberat sebanyak 35 kasus $(53,1 \%)$. Dari 66 sampel yang didapatkan 57 orang $(86,4 \%)$ tidak terdapat gangguan kesadaran.

Tabel 2. Distribusi frekuensi berdasarkan kelompok umur

\begin{tabular}{lcc}
\hline \multicolumn{1}{c}{ Umur } & $\mathbf{n}$ & $\%$ \\
\hline$\leq 30$ tahun & 2 & 3,0 \\
$31-40$ tahun & 7 & 10,6 \\
$41-50$ tahun & 20 & 30,3 \\
$51-60$ tahun & 25 & 37,9 \\
$\geq 61$ tahun & 12 & 18,2 \\
\hline Jumlah & 66 & 100
\end{tabular}

Tabel 2 menunjukan distribusi frekuensi berdasarkan kelompok umur, paling banyak berada pada rentang umur 51-60 tahun yaitu sebanyak 25 orang $(37,9 \%)$, diikuti rentang umur $41-50$ tahun yaitu sebanyak 20 orang $(30,3 \%)$. Rata-rata umur penderita adalah 51,8 tahun $(S D=10,8)$ dan range $16-80$ tahun.

Tabel 3. Distribusi sirosis hepatis berdasarkan klasifikasi Child Pugh

\begin{tabular}{cccccc}
\hline \multicolumn{2}{c}{ Chid A } & \multicolumn{2}{c}{ Chid B } & \multicolumn{2}{c}{ Child C } \\
\hline $\mathbf{n}$ & $\%$ & $\mathbf{n}$ & $\%$ & $\mathbf{n}$ & $\%$ \\
\hline 6 & 9,1 & 29 & 43,9 & 31 & 47 \\
\hline
\end{tabular}

Pada Tabel 3 terlihat distribusi frekuensi berat ringannya sirosis hepatis berdasarkan klasifikasi child pugh paling banyak berada pada Child $\mathrm{C}$ yaitu 31 orang $(47,0 \%)$.

Tabel 4. Derajat varises esofagus

\begin{tabular}{cccccc}
\hline \multicolumn{2}{c}{ Derajat 1 } & \multicolumn{2}{c}{ Derajat 2 } & \multicolumn{2}{c}{ Derajat 3 } \\
\hline $\mathbf{n}$ & $\mathbf{\%}$ & $\mathbf{n}$ & $\mathbf{\%}$ & $\mathbf{n}$ & $\mathbf{\%}$ \\
\hline 9 & 13,6 & 10 & 15,2 & 47 & 71,2 \\
\hline
\end{tabular}

Tabel 4 menunjukan pasien sirosis hepatis paling banyak menderita varises esofagus yang besar, yaitu derajat III (FIII) sebanyak 47 orang $(71,2 \%)$.

Tabel 5. Distribusi frekuensi derajat varises esofagus berdasarkan beratnya sirosis hepatis

\begin{tabular}{|c|c|c|c|c|c|c|}
\hline \multirow{3}{*}{$\begin{array}{c}\text { Variabel } \\
\text { Klasifikasi } \\
\text { Child }\end{array}$} & \multicolumn{4}{|c|}{ Derajat Varises Esofagus } & \multirow{2}{*}{\multicolumn{2}{|c|}{ Total }} \\
\hline & & -FII & & IIII & & \\
\hline & $\mathbf{n}$ & $\%$ & $\mathbf{n}$ & $\%$ & $\mathbf{n}$ & $\%$ \\
\hline $\begin{array}{l}\text { Child A-B } \\
\text { (ringan-sedang) }\end{array}$ & 14 & 21,2 & 21 & 31,8 & 35 & 53 \\
\hline Child C (berat) & 5 & 7,6 & 26 & 39,4 & 31 & 47 \\
\hline Total & 19 & 28,8 & 47 & 71,2 & 66 & 100 \\
\hline
\end{tabular}

Pada Tabel 5 terlihat penderita sirosis hepatis terbanyak berada pada Child $\mathrm{C}$ dengan varises esofagus grade III (FIII) sebanyak 26 orang (39,4\%) diikuti dengan Child A-B dengan varises esofagus grade III (FIII) sebanyak 21 orang (31,8\%). Terdapat hubungan yang bermakna antara beratnya sirosis hepatis dengan derajat varises esophagus.

\section{PEMBAHASAN}

Berdasarkan penelitian yang dilakukan dari rekam medik pasien di Bagian Penyakit Dalam RSUP Dr. M. Djamil Padang pada periode 1 Januari 2012 sampai dengan 31 Desember 2013 didapatkan pasien 
sirosis hepatis sebanyak 422 orang dan pasien sirosis hepatis dengan varises esofagus sebanyak 194 orang (46\%). Penelitian yang dilakukan oleh Karina mendapatkan varises esofagus sebagai komplikasi tersering yang terjadi yaitu sebanyak 44 dari 67 kasus sirosis hepatis. Menurut kepustakaan, sekitar 50\% pasien dengan sirosis hepatis akan mengalami varises dan frekuensi varises esofagus sekitar $30 \%-70 \%$ dari keseluruhan varises. ${ }^{12,13}$

Pada penelitian ini, insiden sirosis hepatis lebih banyak dialami laki-laki daripada perempuan dengan perbandingan 3:1. Hasil ini sama dengan penelitian Tio di RS Soedarso Pontianak. Data ini tidak jauh berbeda dengan yang didapatkan oleh Karina di RSUP Dr. Kariadi Semarang dimana perbandingan laki-laki dan perempuan adalah 2:1 dan Soleh di RS Margono Soekarjo Purwokerto dengan perbandingan laki-laki dan perempuan sebanyak 2,5:1. ${ }^{12,14}$

Pada penelitian ini didapatkan pasien sirosis hepatis berada pada rentang umur 16-80 tahun dan kelompok terbanyak pada umur 51-60 tahun (37,9\%), dengan rata-rata umur penderita adalah 51,8 tahun. Hasil senada dilaporkan oleh Tambunan di Pontianak bahwa sirosis hepatis paling banyak ditemukan pada rentang umur 50-59 tahun (31\%) dengan rerata umur 51,5 tahun. Sedangkan Regina di RSUP M. Djamil Padang, mendapatkan umur terbanyak berada pada rentang $44-50$ tahun $(35,4 \%)$ dengan rerata umur 50,26 tahun. ${ }^{7,8}$

Kusumobroto menyebutkan bahwa sirosis hepatis merupakan salah satu penyakit kronis yang dalam perkembangannya membutuhkan waktu bertahun-tahun hingga menimbulkan gejala dan penderita sirosis hepatis berada pada rentang umur 13-88 tahun. Tarigan menyebutkan bahwa kejadian sirosis hepatis terbanyak pada dekade kelima. ${ }^{14,15}$

Berdasarkan beratnya kerusakan hati yang dinilai dengan menggunakan skor Child pugh didapatkan Child A 9,1\%, Child B 43,9\%, dan Child C yang merupakan kondisi tersering yaitu $47,0 \%$. Hasil ini sama dengan yang dilaporkan oleh Tambunan di Pontianak, dimana penderita sirosis hepatis dengan Child A 3,3\%, Child B 37,5\% dan Child C 53,3\%. Kusnanto di RS Cipto Mangunkusumo, RS Gatot Subroto dan RS Kraton mendapatkan Child A 6,8\%, Child B 36,4\% dan Child C 56,8\%. Begitu juga Juliana
(2009) di Denpasar mendapatkan penderita sirosis Child A sebanyak 7,7\%, Child B 46,2\% dan Child C sebanyak $46,2 \%{ }^{8}$

Sirosis hepatis merupakan silent disease dimana sebagian besar penderita tetap asimptomatis sampai kerusakan hatinya sudah berat baru timbul gejala. Stadium awal sirosis hepatis sering ditemukan secara kebetulan saat pasien melakukan pemeriksaan kesehatan rutin. Pada beberapa pasien, komplikasi dapat menjadi gejala pertama yang membawa pasien pergi kedokter. ${ }^{15}$ Gejala akibat komplikasi ini lebih banyak muncul pada penderita sirosis hepatis dengan derajat penyakit sedang dan berat. ${ }^{17}$ Derajat penyakit sirosis hepatis dapat dinilai dengan menggunakan klasifikasi child pugh. ${ }^{15}$ Penilaian lainnya terhadap beratnya kerusakan hati pada sirosis hepatis dapat menggunakan skor Model for Eng Stage Liver Disease (MELD). ${ }^{9}$

Varises esofagus merupakan salah satu komplikasi terbanyak pada sirosis hepatis. Varises esofagus biasanya baru memberikan gejala apabila varises sudah pecah dengan timbulnya hematemesis atau melena. Semakin tinggi derajat varises esofagus maka semakin tinggi juga kemungkinan untuk terjadinya perdarahan, sehingga akan lebih banyak penderita yang ditemukan dengan varises esofagus stadium berat. $^{15}$

Penelitian ini mendapatkan bahwa penderita sirosis hepatis paling banyak menderita varises esofagus dejarat III (FIII) 71,2\% dilanjutkan dengan derajat II (FII) 15,2\% dan paling sedikit varises esofagus dejarat I (FI) 13,6\%. Vidyani melaporkan varises esofagus grade II-III sebanyak $74,3 \%$ dan varises esofagus grade I sebanyak $25,7 \%$. Penelitian Miro, jumlah varises berdasarkan gradenya tidak jauh berbeda, dimana grade II dan III sama-sama sebanyak 26 orang $(33,8 \%)$ dan pada grade I sebanyak 25 orang $(32,4 \%) .^{18,19}$

Varises esofagus adalah komplikasi tersering sirosis hepatis, sehingga apabila diagnosis sirosis hepatis sudah ditegakkan hendaknya dilakukan pemeriksaan esofagogastroduodenoskopi (EGD) untuk skrinning varises esofagus guna mencegah terjadinya perdarahan dan kematian. Efektivitas skrining dengan endoskopi ini bila ditinjau dari segi biaya masih kontroversi, maka untuk keadaan tertentu 
disarankan menggunakan gambaran klinis dan hasil laboratorium guna membantu memprediksi pasien yang cenderung mempunyai ukuran varises yang besar. $^{20}$

Hasil penelitian ini terlihat penderita sirosis hepatis yang memenuhi Child $C$ sebanyak 31 orang (47\%) dengan varises esofagus derajat III (FIII) sebanyak 26 orang $(39,4 \%)$ yang merupakan kondisi terbanyak dan varises esofagus derajat I-II (FI-FII) 5 orang (7,6\%). Pada Child A-B didapatkan penderita sebanyak 35 orang (53\%) lebih banyak berada pada varises derajat III (FIII) 21 orang (31,8\%), dan varises esofagus derajat I-II (FI-FII) sebanyak 14 orang $(21,2 \%)$. Analisis statistik dengan menggunakan uji chi-square didapatkan hubungan bermakna antara derajat varises esofagus berdasarkan beratnya sirosis hepatis $(p=0,033)$. Hasil penelitian yang sama dilaporkan oleh Miro, S dimana pada Child A ditemukan $83,3 \%$ penderita pada varises esofagus derajat I, pada Child B ditemukan paling banyak varises esofagus derajat II $74,1 \%$ dan Child C ditemukan varises esofagus derajat III $84,6 \%{ }^{19}$ Setelah diuji secara statistik didapatkan korelasi positif yang kuat dengan nilai $r=0,79(p<0,05)$.

\section{SIMPULAN}

Terdapat hubungan antara beratnya sirosis hepatis dengan derajat varises esofagus.

\section{UCAPAN TERIMA KASIH}

Terima kasih kepada berbagai pihak atas bimbingan, bantuan dan motivasi dalam penelitian ini.

\section{DAFTAR PUSTAKA}

1. Widjaja FF, Karjadi T. Pencegahan perdarahan berulang pada pasien sirosis hati. J Indon Med Assoc. 2011;61:418-24.

2. Sherlock S, Dooley J. Hepatic Cirrhosis. Dalam: Diseases of the liver an billiary system. Edisi ke-10. Blackwell Science Publication. 1997;371-84.

3. Jang JW. Current Status of Liver Diseases in Korea. Korean J Hepatol. 2009;15:40-9.

4. PPHI-INA ASL. Sirosis hepatis. (diunduh 9 November 2013). Tersedia dari: URL: HYPERLINK http://pphi-online.org/alpha/?p=570\#more-570.
5. Ilhami F. Gambaran sirosis hepatis di bagian penyakit dalam RSUP Dr. M. Djamil Padang Periode 1999 sampai Desember 2000 (skripsi). Padang: Fakultas Kedokteran Universitas Andalas: 2001.

6. Oktora MZ. Hubungan kadar hemoglobin dan jumlah trombosit dengan berat sirosis hati terhadap penyakit yang di rawat di bagian penyakit dalam RS Dr.M.Djamil Padang (skripsi). Padang: Fakultas Kedokteran Universitas Andalas: 2007.

7. Regina V. Hubungan kadar limfosit total dengan prognosis penyakit pada penderita sirosis hati di bagian penyakit dalam RS Dr. M. Djamil Padang tahun 2011 (skripsi). Padang: Fakultas Kedokteran Universitas Andalas; 2013.

8. Tambunan A. Karakteristik pasien sirosis hati di RSUD dr. Soedarso Pontianak periode Januari 2008 - Desember 2010. Pontianak: Fakultas Kedokteran Universitas Tanjungpura. 2012.

9. Nurdjanah S. Sirosis hati. Dalam: Sudoyo AW, Setiyohadi B, Alwi I, Simadibrata KM, Setiati S. Buku ajar ilmu penyakit dalam jilid I. Edisi ke-5.. Jakarta: Balai Penerbit FKUI. 2009.

10. Netiana, Juniati SH. Varises esofagus (artikel IImiah). Surabaya: Fakultas Kedokteran Universitas Airlangga; 2011.

11. Sudoyo AW, Setiyohadi B, Alwi I, Simadibrata KM, Setiati S. Buku ajar ilmu penyakit dalam jilid I. Edisi ke-5. Jakarta: Balai Penerbit FKUI; 2009.

12. Karina. Faktor resiko kematian penderita sirosis hati di RSUP Dr. Kariadi Semarang tahun 20022006 (karya tulis ilmiah). Semarang: Fakultas Kedokteran Universitas Diponegoro; 2007.

13. Block B, Schachschal G, Schmidt H. Esophageal varices. Dalam: Block B, Schachschal G, Schmidt $\mathrm{H}$, editor (penyunting). Endoscopy of the upper $\mathrm{GI}$ Tract. Germany: Grammlich; 2004.hlm.85-150.

14. Tio AS, Cika. Hubungan Komplikasi skor ChildTurcotte dan usia lanjut sebagai faktor resiko kematian pada pasien sirosis hati di RSUD DR. Soedarso Pontianak tahun 2008-2012 (naskah publikasi). Pontianak: Fakultas Kedokteran Universitas Tanjungpura; 2013.

15. Kusumobroto $\mathrm{OH}$. Buku ajar ilmu penyakit hati. Edisi ke-1. Jakarta: Jayabadi; 2007. 
16. Tarigan P. Sirosis hati. Dalam: Noer $S$, Waspadji S, Rachman AM, editor (penyunting). IImu Penyakit Dalam Jilid I. Jakarta: Balai Penerbit FKUI; 2009.

17. Heidelbaugh JJ, Sherbondy M. Cirrhosis and chronic liver failure. Part II: complications and traetment. Am Fam Physician 2006;74:765-74.

18. Vidyani A, Denny V, Budi W. Faktor resiko terkait perdarahan varises esofagus berulang pada penderita sirosis hati (artikel ilmiah). Surabaya: Fakultas Kedokteran Universitas Airlangga; 2011.
19. Miro S. Hubungan antara parameter non-invasif dengan derajat varises esofagus pada sirosis hati (tesis). Padang: Fakultas Kedokteran Universitas Andalas; 2007.

20. John R, Saltzman S. Acute upper gastrointestinal beeding. Dalam: Greenberger N, Blumberg R, Burakoff R, editor (penyunting). Current diagnosis and treatment: gastroenterolgy. Hepatology \& Endoscopy. Edisi ke-2. USA: McGraw Hill Companies Inc; 2009.hlm.324-42. 